Research Article

\title{
Highly Conductive and Soluble Polymer Synthesized by Copolymerization of Thiophene with Para- Methoxybenzaldehyde Using Clay Catalyst
}

Djamal Eddine Kherroub ${ }^{1, *}$, Larbi Bouhadjar ${ }^{2}$, Boukoussa Bouhadjar ${ }^{3}$, Abdelkader Rahmouni ${ }^{1}$, Khadidja Dahmani ${ }^{4}$, Mohammed Belbachir ${ }^{1}$

${ }^{1}$ Laboratoire de Chimie des Polymères, Université Ahmed Ben Bella d'Oran1, BP 1524, El-Mnaouer, 31000 Oran, Algeria

${ }_{2}^{2}$ Faculté des Sciences de la Matière, Université Ibn Khaldoun de Tiaret, BP P78, Zaâroura, 14000 Tiaret, Algeria

${ }^{3}$ Laboratoire de Chimie des Matériaux, Université Ahmed Ben Bella d'Oran1, BP 1524, El-Mnaouer, 31000 Oran, Algeria

${ }^{4}$ Centre Universitaire Ahmed Zabana de Relizane, BP 48000, Bourmadia, Relizane, Algeria

Received: 17th December 2018; Revised: $10^{\text {th }}$ February 2019; Accepted: $15^{\text {th }}$ February 2019; Available online: 30th April 2019; Published regularly: 1st August 2019

\section{Abstract}

This present research focuses on the synthesis of a new conducting polymer based on the copolymerization of thiophene with para-methoxybenzaldehyde, using a clay as an ecologic catalyst named Maghnite- $\mathrm{H}^{+}$. The catalysis of the reaction by Maghnite- $\mathrm{H}^{+}$can confer it important benefits, such as the green environment aspect. The reaction was carried out in dichloromethane as a solvent. The new copolymer obtained is a poly (heteroarylene methines) small bandgap polymers precursor. It can be considered as a useful model system for examining the impacts of $\Pi$-conjugation length on the electronic properties of this type of conjugated polymers. The measurements of the electrical conductivity gave a value of order of $0.0120 \Omega . \mathrm{cm}^{-1}$, allowing its use in various important applications. The characteristics of the molecular structure and the thermal behavior of the conducting polymer obtained are also discussed using different methods of analysis, such as: proton nuclear magnetic resonance (NMR), Fourier transform infrared (FTIR) spectroscopy, ultraviolet/visible spectroscopy, and thermal gravimetric analysis (TGA). Copyright (C) 2019 BCREC Group. All rights reserved

Keywords: Clay; Maghnite-H+; Poly[(thiophene-2,5-diyl)-co-(para-methoxylbenzylidene)]; Bandgap; electrical conductivity.

How to Cite: Kherroub, D.E., Bouhadjar, L., Bouhadjar, B., Rahmouni, A., Dahmani, K., Belbachir, M. (2019). Highly Conductive and Soluble Polymer Synthesized by Copolymerization of Thiophene with Para-Methoxybenzaldehyde Using Clay Catalyst. Bulletin of Chemical Reaction Engineering \& Catalysis, 14(2): 413-420 (doi:10.9767/bcrec.14.2.3793.413-420)

Permalink/DOI: https://doi.org/10.9767/bcrec.14.2.3793.413-420

\section{Introduction}

The clay minerals are the nanofillers that present a high interest from the scientific re-

* Corresponding Author.

E-mail: djamaleddine.kherroub@yahoo.com (D.E. Kherroub);

Telp: +213-79-5565299, Fax: +213-41-581413 searchers. They are considered micro-reactors because they are capable of concentrating large quantities of these reactive species between their aluminosilicate layers. The presence of water in the clay minerals and the existence of structural defects make these inorganic solids effective. Lewis and Brönsted acids (some clays 
are called "proton sponges" and are characterized by acidity similar to that of inorganic strong acids) [1,2]. Clay minerals were used as solid catalysts instead of strong acids such as hydrochloric acid and para-toluenesulfonic acid. The clay minerals are easily removed from the solution of reagents by simple filtration and can be reused many times without loss of activity $[3,4]$. Clays of the smectite type having a basal distance of $10 \AA$ and compensating cations or exchangeable cations, including at least 10 meq/100 g dry are cations of the type of those belonging to the class of hard acids. Among the cations belonging to this class, mention will advantageously be the cations $\mathrm{Al}^{3+}, \mathrm{H}^{+}, \mathrm{Ce}^{3+}$, and $\mathrm{Zr}^{4+}$ [5-9]. In general, for obtaining the catalytic clays, the process consists in bringing into contact starting clay of the smectic type of any origin with a salt of a cation belonging to the class of strong acids, this treatment step should followed by another dehydration step. The chemical and physical properties of the mineral clay depend strongly on the amount of water present between the layers. Clay minerals have catalytic properties in the polymerization reactions of several cyclic and siloxane monomers due of the surface acidity, which have been the subject of huge number of studies [10-16].

Developing conducting materials that can be use in the new technology is of highly desired in different field of sciences $[17,18]$. Research on conducting polymers gained great momentum in the past decade. These new materials are considered as a great potential candidate for wide range of applications such as sensors, electronic components (aeronautics, astronautics), electrical conductors, solar cells and it can be use as light emitting diodes LEDs [1921]. Currently, many works are focuses on tailoring the properties of conducting materials (polymers) such as solubility, reactivity and compatibility to be adapted to the new applica- tions. Conjugated or conducting polymers, such as: polythiophene and its derivatives, are the subject of huge number of researches focusing on their outstanding properties as the good chemical and thermal stability, gas permeability, flame retardance and electrical conductivity. Conducting polymers properties which make these new materials interesting are heavily dependent on catalysis and synthetic procedures. Recently, a lot of searches have been carried out focusing on developing the properties of these polymers by copolymerization [22], incorporating of nanoparticles and composite with other materials [23,24]. The copolymers include two or more different monomeric units obtained via copolymerization reaction in the aim to developing materials properties bring together the characteristics and properties of all the monomeric units constituting the copolymer. The disadvantage of the majority of small band gap organic polymer conductors, synthesized in previous research, such as: polythiophene, polypyrrole, etc., is their insolubility, that is why we proposed in our work to copolymerize these polymers with others for that they raise the criterion of solubility. The copolymerization of thiophene with an aldehyde serves to have a conductive material soluble in conventional solvents, which makes it possible to extend the field of use of these materials [25-27].

In this present study, we describe an efficient method adopted to synthesize a new conductive polymer based on thiophene and benzaldehyde in the presence of modifying clay named Maghnite- $\mathrm{H}^{+}$, this clay was obtained by the exchange with hydronium ions (Scheme 1). The copolymer material obtained was subjected to different characterization methods in order to identify its molecular structure. Its thermal stability has also been evaluated. The influence of the amount of catalyst used, temperature

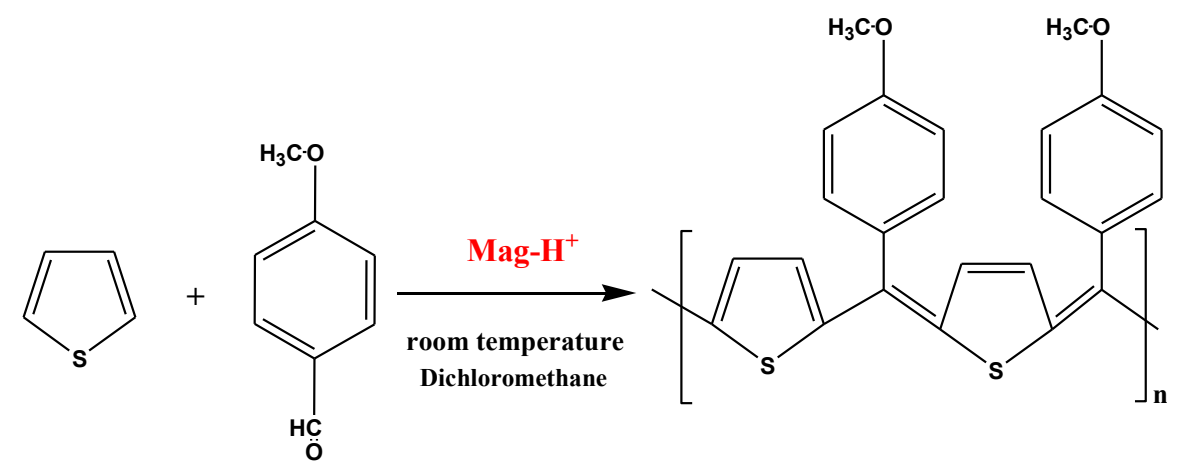

Thiophene para-methoxybenzaldehyde

PTMB

Scheme 1. The synthetic route of the synthesis of PTMB by Mag- $\mathrm{H}^{+}$catalyst 
and time were studied by changing each time a single parameter.

\section{Materials and Method}

\subsection{Materials}

Thiophene $\left(\mathrm{C}_{4} \mathrm{H}_{4} \mathrm{~S}, 99 \%\right)$, dichlorimethene $\left(\mathrm{CH}_{2} \mathrm{Cl}_{2}\right.$, 99.8\%) and para-methoxybenzaldehyde $\left(\mathrm{CH}_{3} \mathrm{OC}_{6} \mathrm{H}_{4} \mathrm{CHO}, 98 \%\right)$ were purchased from Aldrich Chemical Co, without further purification. Maghnite was obtained from Algerian company of bentonite (BENTAL), without any pretreatment.

\subsection{Catalyst Preparation}

Maghnite- $\mathrm{H}^{+}$was obtained by stirring a mixture of Raw-Maghnite and sulfuric acid $0.25 \mathrm{M}$ at room temperature until the saturation was achieved over a two day period, After that solution was filtered washed continuously with deionized water to remove all trace of sulfate ions, allowed to dried in an oven at $105^{\circ} \mathrm{C}$ and finely ground for further using. The clay cation exchange capacity (CEC) was found to be $84 \mathrm{meq} / 100 \mathrm{~g}$ of dried clay [6].

\subsection{Polymer Synthesis}

The copolymerization of the monomers (thiophene and para-methoxybenzaldehyde)

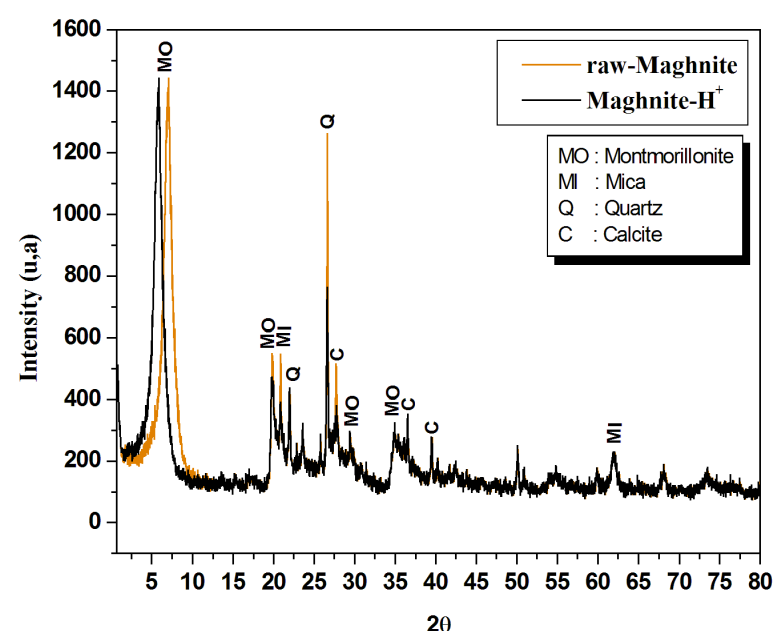

Figure 1. X-ray Diffraction of Raw-Maghnite and $\mathrm{Mag}-\mathrm{H}^{+} 0.25 \mathrm{M}$ using the Mag- $\mathrm{H}^{+}$as catalyst took place in solution under inert atmosphere (nitrogen). On the other hands, different amounts of $\mathrm{Mag}-\mathrm{H}^{+}$ was dried at $100{ }^{\circ} \mathrm{C}$ for one hour. Mag- $\mathrm{H}^{+}$was used to catalyst the polycondensation of thiophene (7 $\mathrm{mmol})$ and para-methoxybenzaldehyde $(7 \mathrm{mmol})$ dissolved in dichloromethane. The solution was then placed under stirring within 6 hours polymerization period at room temperature. The resulting mixture was separated from the clay. It was then collected and allowed to dry for 24 hours at room temperature. The reaction yield was calculated by weighing as follows:

Yield $(\%)=\frac{\text { Mass of the polymer obtained }}{\text { Mass of reagents }} \times 100$

\subsection{Characterization Methods}

The functional groups of PTMB were identified using various methods of analysis such as Perkin-Elmer FT-IR spectroscopy, ${ }^{1} \mathrm{H}-\mathrm{NMR}$, and ${ }^{13} \mathrm{C}-\mathrm{NMR}$ (300 $\mathrm{MHz}$ Bruker) and UV-Vis spectroscopy (OPTIZEN 2120), The thermal stability of PTMB was performed by Labsys Evo Setaram thermogravimetric model operating under helium gas at flow rate of $10^{\circ} \mathrm{C} / \mathrm{min}$. The electric conductivity values were given using a four-probe technique in ECOPIA HALL EFFECT, HMS-3000 VER 3.51.5.

\section{Results and Discussion}

3.1 XRD Characterization of Maghnite and Maghnite- $\mathrm{H}^{+}$

The X-ray diffraction patterns powder of Maghnite and Maghnite- $\mathrm{H}^{+}$(Figure 1) revealed the presence of different crystalline phases such as montmorillonite, quartz, mica and calcite. Under acid treatment, the rate of mica, quartz and calcite were decreased, this has been deduced from the decrease in the intensity of the corresponding peaks respectively located at 21,23 , and $25^{\circ}$. The shift of the dominant peak corresponding to montmorillonite from 12.5 to $15.02 \AA$ after acid treatment is explained by the increase in basal spacing. The increase in this gap between the layers of montmorillonite is due to the replenishment of

Table 1. Elementary compositions of Maghnite and Maghnite- $\mathrm{H}^{+}$(compositions by wt \%).

\begin{tabular}{cccccccccc}
\hline Sample & $\mathrm{SiO}_{2}$ & $\mathrm{Al}_{2} \mathrm{O}_{3}$ & $\mathrm{Fe}_{2} \mathrm{O}_{3}$ & $\mathrm{CaO}$ & $\mathrm{MgO}$ & $\mathrm{Na}_{2} \mathrm{O}$ & $\mathrm{K}_{2} \mathrm{O}$ & $\mathrm{TiO}_{2}$ & $\mathrm{SO}_{3}$ \\
\hline 60 & 69.36 & 14.67 & 1.16 & 0.30 & 1.07 & 0.50 & 0.79 & 0.16 & 0.91 \\
70 & 71.70 & 14.03 & 0.71 & 0.28 & 0.8 & 0.21 & 0.77 & 0.15 & 0.34 \\
\hline
\end{tabular}


interlamellar cations originally existed by bulky hydronium ions from the acid treatment. Similar basal spacings have been obtained by other researchers using other clays. Kooly et al. obtained a basal spacing of $15.4 \AA$ for Ca-rich montmorillonite acid treatment with $\mathrm{H}_{2} \mathrm{SO}_{4}$ at $90{ }^{\circ} \mathrm{C}$ [28]. Hashizu recorded a value of $15.6 \AA$ for the treatment of Japanese montmorillonite (Kunipia-F) with $\mathrm{HCl}(\mathrm{pH}=4)$ [29]. Particular, we note that the acid treatment of the Maghnite increase the basal spacing but did not affect the original structure of the montmorillonite which was confirmed by the no change in the $\mathrm{x}$-ray characteristic peak. Table 1 provides the chemical composition of Maghnite before and after treatment with sulfuric acid.

\subsection{Characterization of Obtained Polymer}

\subsubsection{UV-Visible spectroscopy}

The UV-Vis spectra of the PTMB obtained displayed a high solubility in organic solvents such as dichloromethane, Tetrahydrofuran, $\mathrm{N}, \mathrm{N}$-dimethylformamide and chloroform. The PTMB gives grey solutions of high concentrations and possess conjugated chains due to the degree of dehydrogenation. The very good solubility of polymers in spite of their high degree of $\Pi$-conjugation is might be due largely to the bulky side groups $(\Phi)$ at the methane carbon $=$ C (Ф) link and also to the low molecular weight to some extent.

Figure 2 demonstrates the UV-Vis spectrum of the PTMB in dichloromethane. The polymer solution was brown or almost black. The adsorption spectrum indicate the presence of three bands of absorption located at $260 \mathrm{~nm}$, $272 \mathrm{~nm}$ and in the range of $420-480$, assigned

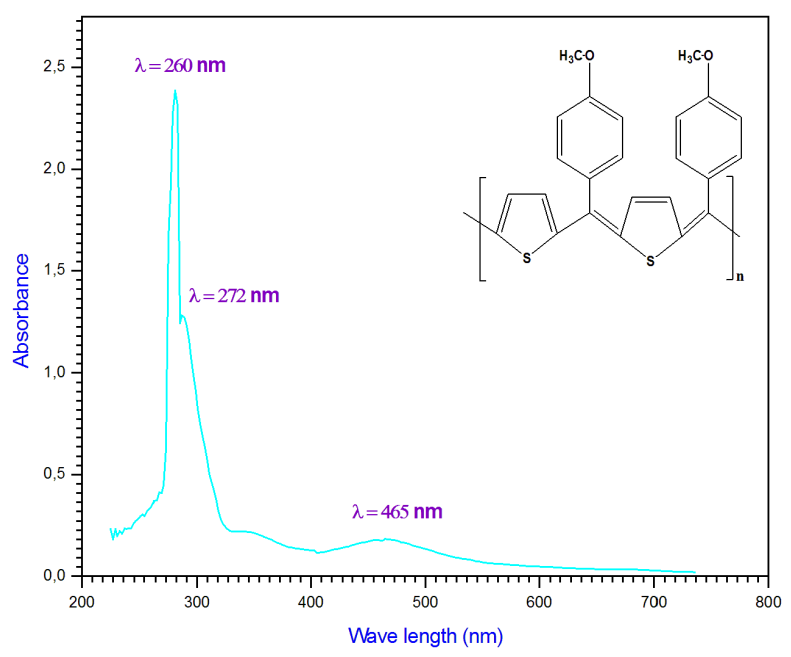

Figure 2. UV-visible spectrum of PTMB (in $\mathrm{CH}_{2} \mathrm{Cl}_{2}$ ). to the phenyl chromophore, the $\pi-\pi^{*}$ transition of the aromatic heterocycles and the $\pi-\pi^{*}$ transition of the methine bridge formed respectively. It can be clearly seen that the PTMB absorb visible light.

\subsection{2 ${ }^{1} \mathrm{H}-\mathrm{NMR}$ spectroscopy}

The ${ }^{1} \mathrm{H}-\mathrm{NMR}$ spectrum of PTMB was obtained to further investigate and confirm the proposed structure. Figure 3 demonstrate the ${ }^{1} \mathrm{H}$-NMR spectrum of PTMB in DMSO. The $\mathrm{H}_{\mathrm{a}}$ protons appear at $3.72 \mathrm{ppm}(3 \mathrm{H}, \mathrm{s}), \mathrm{H}_{\mathrm{b}}$ at 6.85 ppm $(2 \mathrm{H}, \mathrm{d}, \mathrm{J}=7.15 \mathrm{~Hz})$ and $\mathrm{H}_{\mathrm{c}}$ at $7.11 \mathrm{ppm}$ $(2 \mathrm{H}, \mathrm{d}, \mathrm{J}=7.35 \mathrm{~Hz})$ correspond to phenyl protons. The thiophene protons $\mathrm{H}_{\mathrm{d}}$ are located at $7.49 \mathrm{ppm}(2 \mathrm{H}, \mathrm{d}, \mathrm{J}=4.11 \mathrm{~Hz})$. The small peak at $5.56 \mathrm{ppm}(2 \mathrm{H}, \mathrm{s})$ is attributed to $\mathrm{CH}_{2}$ protons at the end of the polymer chain. The quasi-equality of the $\mathrm{H}_{\mathrm{b}}$ and $\mathrm{H}_{\mathrm{c}}$ proton integration

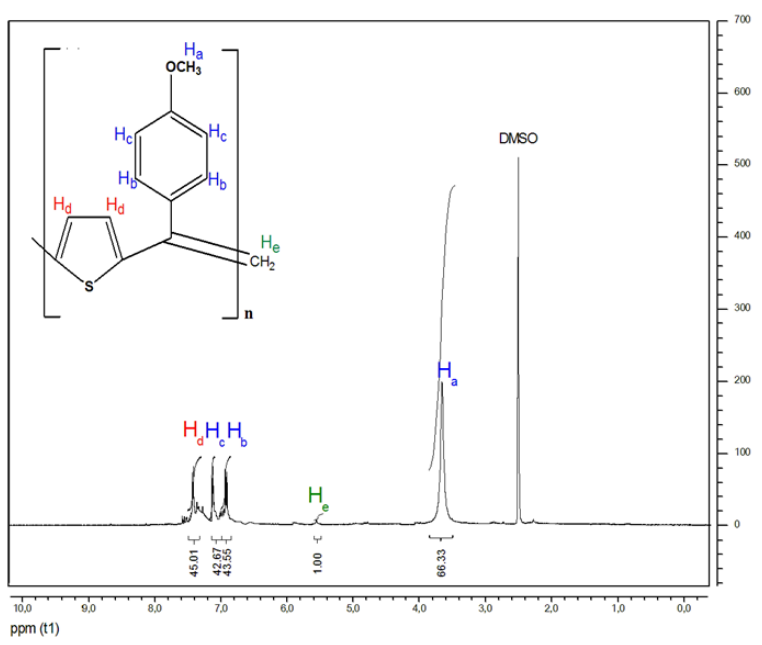

Figure 3. ${ }^{1} \mathrm{H}-\mathrm{NMR}$ spectrum $(300 \mathrm{MHz})$ of PTMB in DMSO.

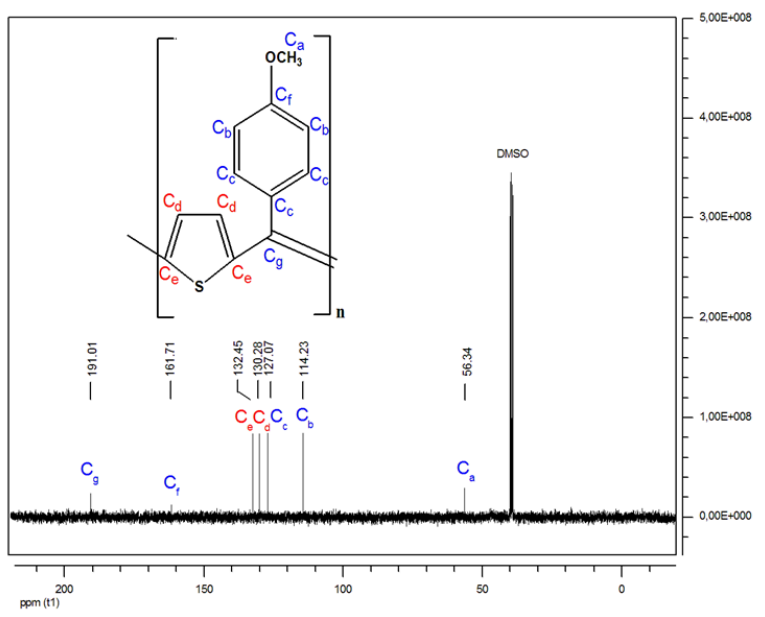

Figure 4. ${ }^{13} \mathrm{C}-\mathrm{NMR}$ spectrum $(300 \mathrm{MHz})$ of PTMB in DMSO. 
curves of benzene and thiophene $\mathrm{H}_{\mathrm{d}}$ indicates that the attachment of two monomers was alternately. The comparison of the value of these integration curves and that of the proton at the end of the chain makes it possible to calculate the number-average molecular weight, it is found to be about $6800 \mathrm{~g} / \mathrm{mol}$.

\subsection{3 ${ }^{13} \mathrm{C}-\mathrm{NMR}$ spectroscopy}

Figure 4 shows the ${ }^{13} \mathrm{C}-\mathrm{NMR}$ spectrum of the obtained polymer. This characterization technique was carried out in order to complete the information collected by ${ }^{1} \mathrm{H}-\mathrm{NMR}$, for identifying and confirming the molecular structure much more in terms of the nature of the existing carbonic groups. The carbon of the methoxy group appears at $56.34 \mathrm{ppm}$. The carbons of the benzene ring located in the ortho, meta and para position to methoxy group are observed at 114.23 and $127.07 \mathrm{ppm}$, respectively. The small peak at $161.71 \mathrm{ppm}$ corresponds to the carbon of the benzene ring linked to the methoxy group. The two peaks at 130.28 and 132.45 ppm are attributed to thiophene ring carbons. The original carbon of the aldehyde group appears at $191.01 \mathrm{ppm}$.

Table 2. Electrical properties of PTMB.

\begin{tabular}{ll}
\hline \multicolumn{1}{c}{ Settings } & \multicolumn{1}{c}{ Results } \\
\hline Time limit & $0.100 \mathrm{~S}$ \\
Measures number & 1000 Times \\
Mobility & $2.487 \mathrm{E}+3(\mathrm{~cm} / \mathrm{Vs})$ \\
Resistivity & $0.933 \mathrm{E}-8(\Omega . \mathrm{cm})$ \\
Conductivity & $0.0120\left(\Omega . \mathrm{cm}^{-1}\right)$ \\
\hline
\end{tabular}

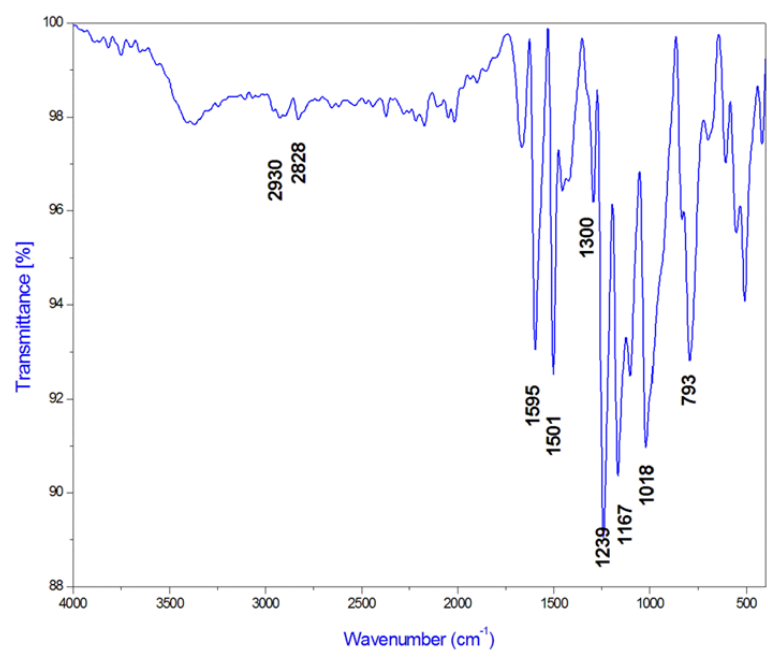

Figure 5. FTIR spectrum of PTMB

\subsubsection{IR spectroscopy}

Figure 5 presents the IR absorption spectrum of PTMB. The two mid-intensity bands at 2930 and $2828 \mathrm{~cm}^{-1}$ correspond to the $\mathrm{C}-\mathrm{H}$ symmetric and asymmetric stretch. The sharp peak at $1595 \mathrm{~cm}^{-1}$ is assigned to $\mathrm{C}=\mathrm{C}$ stretching vibration of the benzene ring in the side chain. The peak at $1501 \mathrm{~cm}^{-1}$ is assigned to the $\mathrm{C}=\mathrm{C}$ stretching vibration bands of the thiophene rings. The mid-intensity band at 1300 $\mathrm{cm}^{-1}$ corresponds to the valence vibration of the $\mathrm{C}-\mathrm{C}$ bond. The peak at $1239 \mathrm{~cm}^{-1}$ is assigned to the valence vibration of the $\mathrm{C}-\mathrm{H}$ bond. The two peaks at 1167 and $1018 \mathrm{~cm}^{-1}$ are assigned to the $\mathrm{C}-\mathrm{O}$. The deformation vibration located at $793 \mathrm{~cm}^{-1}$ corresponds to the deformation of the $\mathrm{C}-\mathrm{S}-\mathrm{C}$ bond. The connection between the two monomers is confirmed by the absence of the aldehyde function. The IR spectrum of the copolymer obtained corroborates to a large extent the proposed structural architecture.

\subsubsection{Thermal analysis}

Figure 6 shows the TGA thermogram of PTMB obtained in a helium atmosphere in the temperature range of 80 to $760{ }^{\circ} \mathrm{C}$ at a heating rate of $10{ }^{\circ} \mathrm{C} / \mathrm{min}$. These data show that the conducting polymer was thermally stable before the temperature $190{ }^{\circ} \mathrm{C}$, after this temperature the PTMB began to degrade in one major step due to the decomposition of polymeric chain.

\subsection{Conductivity Measurements}

For the measurement of the electrical conductivity of the synthesized products, the dip

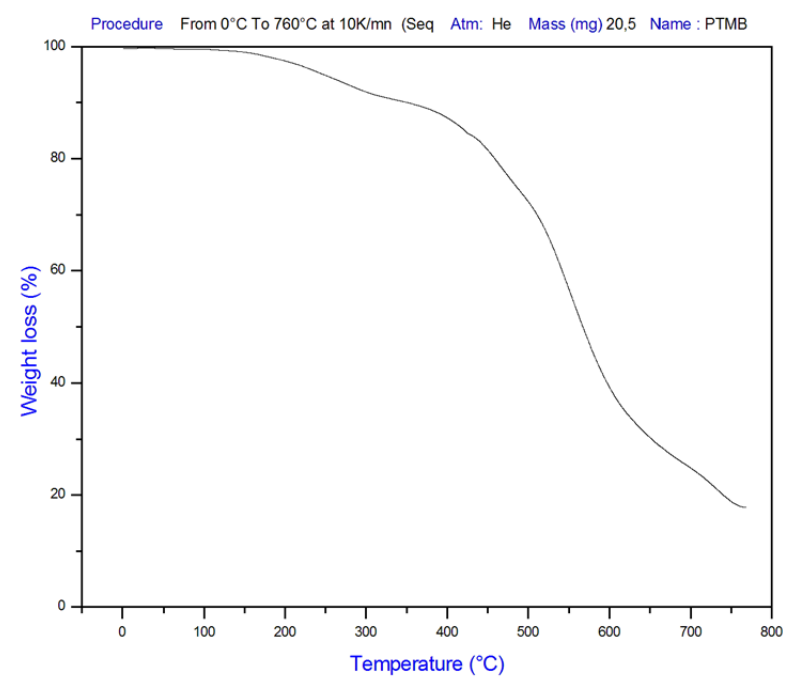

Figure 6. TGA spectrum of PTMB 
coating method was used to cast the thin film on clean $1 \mathrm{~mm}$ thick high quality glass substrates. On other hands deposition glass substrates were cleaned as ultrasonic using acetone, ethanol and then rinsed with distilled water and dried. A thin layer of PTMB solution was dip-coated onto glass substrates. The film of PTMB was dried at room temperature and heated in an oven at $90^{\circ} \mathrm{C}$ for 1 hour to remove moisture. The conductivity measurements were performed with the four point probe technique. The electrical properties of the synthesized polymer are given in Table 2.

\subsection{Solubility Tests}

The solubility of the copolymer was quantified by the solubility test in different solvents such as dichloromethane, Chloroform, THF and DMF by dissolving a $0.2 \mathrm{~g}$ of PTMB in $30 \mathrm{~mL}$ of solvent. The mixture was continuously stirred at room temperature for half-hour. After that the solution was filtered and allowed to be dried completely. Finally, the product was weighed and the solubility was calculated using

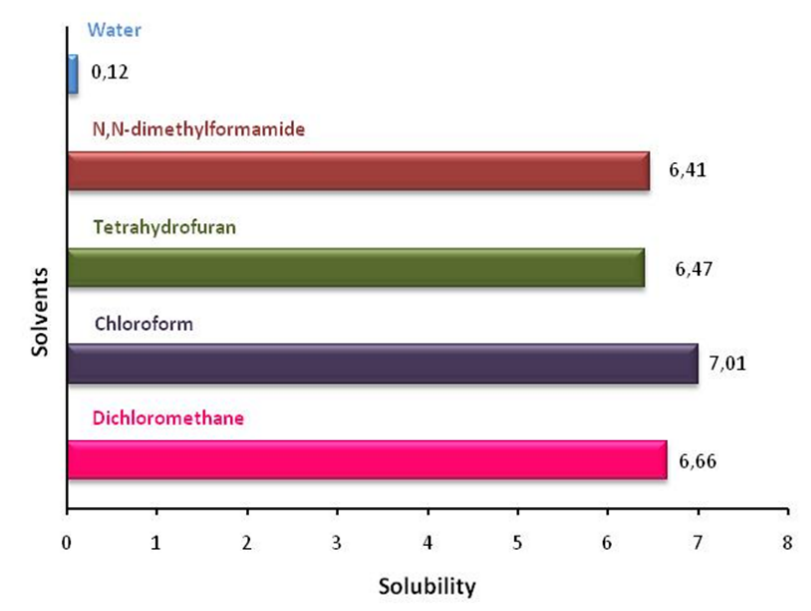

Figure 7. Solubility test results

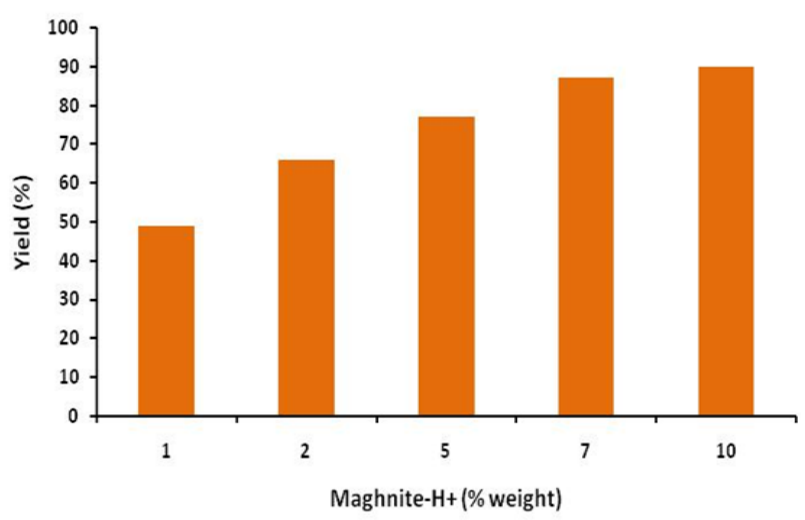

Figure 8. Effect of the Mag- $\mathrm{H}^{+}$amount on the yield of PTMB the following equation. The results obtained are summarized in Figure 7.

Yield $(\%)=\frac{M_{i}-M_{f}}{V_{s}} \times 100 \%$

where $M_{i}$ describes mass of sample before dissolved, $M_{s}$ is mass of undissolved sample, and $V_{s}$ is volume of solvent.

\subsection{Influence of Operating Conditions on Yield}

\subsubsection{Effect of the amount of Maghnite- $\mathrm{H}^{+}$used}

In this part of study we fellow the effect of the amount of $\mathrm{Mag}-\mathrm{H}^{+}$on the synthesis reaction of PTMB. The Figure 8 shows the effect of the amount of Mag- $\mathrm{H}^{+}$on the polymerization rate, investigated by using various weight ratios $\mathrm{Mag}-\mathrm{H}^{+} /$monomer. The polymerization was carried out in solution $\left(\mathrm{CH}_{2} \mathrm{Cl}_{2}\right)$. As shown in Figure 8, a yield of $90 \mathrm{wt} \%$ was reached using $10 \mathrm{wt} \%$ of Mag- $\mathrm{H}^{+}$for $6 \mathrm{~h}$. Similar results were obtained by Yahiaoui et al. and Boutaleb et al. in the polymerization of epichlorhydrin, propylene oxide and cyclohexene oxide by $\mathrm{Mag}-\mathrm{H}^{+}$

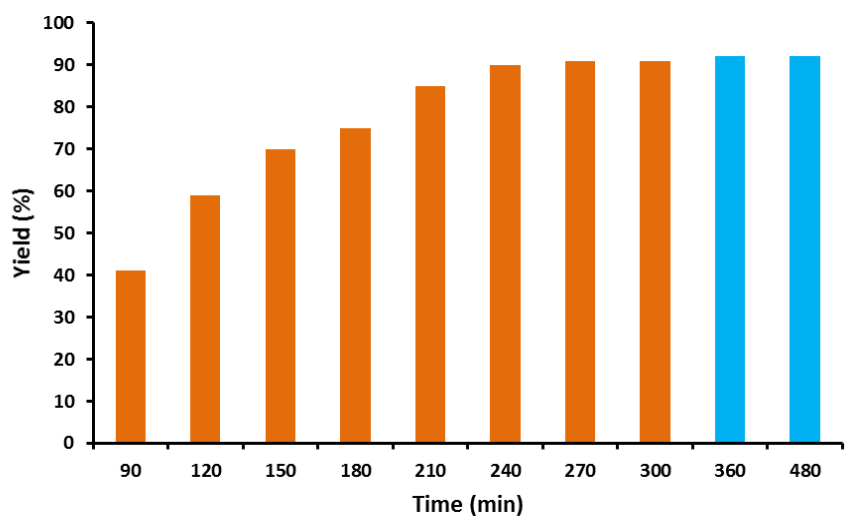

Figure 9. Effect of polymerization duration on yield of PTMB (Solvent $\mathrm{CH}_{2} \mathrm{Cl}_{2}, \mathrm{~T}=25^{\circ} \mathrm{C}$ and $10 \%$ of Mag- $\left.\mathrm{H}^{+}\right)$

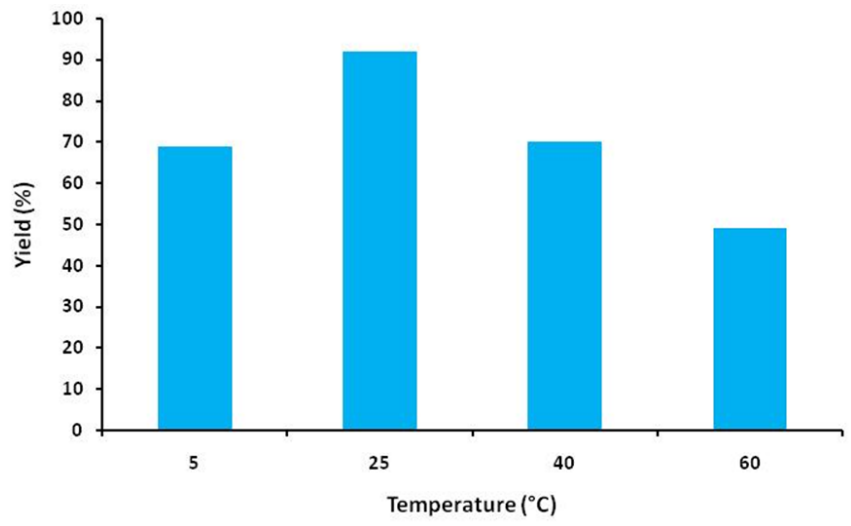

Figure 10. Effect of the temperature on the yield of PTMB 
[30-32]. This phenomenon is probably the result of the number of initiating active sites responsible for the induction of the polymerization, this number is proportional to the amount of catalyst used in the reaction.

\subsubsection{Effect of reaction time}

Figure 9 shows the yield of polymer versus time for polymerization of thiophene with paramethoxybenzaldehyde using Mag- $\mathrm{H}^{+}$as catalyst (10 wt\% of Mag- $\left.\mathrm{H}^{+}\right)$. The polymerization proceeded slowly and gently until it reached a yield of $92 \%$ after $8 \mathrm{~h}$ at $25{ }^{\circ} \mathrm{C}$. The polymerization yield became constant at that time; this is probably the result of the increase in the average viscosity.

\subsubsection{Effect of reaction temperature}

The effect of the temperature on the polymerization of thiophene with paramethoxybenzaldehyde is followed in the present party. The polymerization was carried out for $8 \mathrm{~h}$ in the presence of $10 \mathrm{wt} \%$ of $\mathrm{Mag}-\mathrm{H}^{+}$and [para-methoxybenzaldehyde $]=$ [thiophene $]=$ $7.10^{-1} \mathrm{~mol} / \mathrm{L}$. The results obtained at different temperatures are shown in Figure 10. From these results we conclude that the optimal temperature for the reaction is $25^{\circ} \mathrm{C}$ (the yields reach a maximum).

\section{Conclusion}

The poly [(thiophene-2,5-diyl)-co-(paramethoxybenzylidene)] (PTMB) have been successfully synthesized using Maghnite- $\mathrm{H}^{+}$as a green catalyst. The chemical structure of PTMB has been characterized by different methods of analysis such as UV-Vis, IR and ${ }^{1} \mathrm{H}$ NMR. Thermal analysis TGA showed that PTMB is thermally stable before the temperature $190{ }^{\circ} \mathrm{C}$. Electrical conductivity measurements gave a value of $\sigma=0.0120 \Omega . \mathrm{cm}^{-1}$, this is due to $\Pi$-conjugated bonds along the polymer chain, formed during the reaction. The solubility tests have shown that this new polymer obtained is soluble in common organic solvents such as dichloromethane, chloroform, tetrahydrofuran, etc., which gives it a specific and advantageous character as a conductive material. The study of operating conditions of reaction showed that a yield of $90 \%$ can be achieved with a catalyst mass content of $10 \%$ for 6 hours at $25{ }^{\circ} \mathrm{C}$. Such results can be used primarily to illuminate a novel technique for increasing the solubility of low bandgap polymers based on the arrangement of aromatic heterocycles in the conjugated polymer backbone.

\section{References}

[1] Aldridge, L. (1973). Cracking of n-hexane over LaX catalysts. Journal of Catalysis, 30:409-416.

[2] Forni, L. (1873). Comparison of the Methods for the Determination of Surface Acidity of Solid Catalysts. Catalysis reviews. Science and engineering, 8: 65-115.

[3] Kowalska, M., Cocke, D.L. (1998). Interactions of chloroanilines with natural and ion exchanged montmorillonites. Chemosphere, 36: 547-552.

[4] Evangelou, V.P., Marsi, M., Vandiviere, M.M. (1999). Stability of $\mathrm{Ca}^{2+}-, \mathrm{Cd}^{2+}-, \mathrm{Cu}^{2+}-[$ illitehumic] complexes and $\mathrm{pH}$ influence. Plant and Soil, 213: 63-74.

[5] Ayat, M., Belbachir, M., Rahmouni, A. (2017). Synthesis of block copolymers consists on vinylidene chloride and $\alpha$ - Methylstyrene by cationic polymerization using an acid exchanged montmorillonite clay as heterogeneous catalyst (Algerian MMT). Journal of Molecular Structure, 1139: 381-389.

[6] Belbachir, M., Bensaoula, A. (2001). US Patent. No 6, 274,527B1

[7] Kherroub, D.E., Belbachir, M., Lamouri, S. (2017). Synthesis and characterization of polyvinylmethylsiloxanes by cationic polymerization using a solid green catalyst. $e$ Polymers, 17: 1-11.

[8] Benadda, M., Ferrahi, M.I., Belbachir, M. (2014). Synthesis of Poly(N-vinyl-2pyrrolidone-co-methyl methacrylate) by Maghnite- $\mathrm{H}^{+}$a Non-toxic Catalyst. Bulletin of Chemical Reaction Engineering \& Catalysis, 9: 201-206.

[9] Cornelis, A., Laszlo, P. (1985). ClaySupported Copper(II) and Iron(III) Nitrates: Novel Multi-Purpose Reagents for Organic Synthesis. Synthesis, 10: 909-918.

[10] Kherroub, D.E., Belbachir, M., Lamouri, S. (2018). A new approach for the polymerization of tetraphenyltetramethylcyclotetrasiloxane by an environmentally friendly catalyst called Maghnite- $\mathrm{H}^{+}$. Green Processing and Synthesis, 7: 296-305.

[11] Kherroub, D.E., Khodja, M., Belbachir, M., Lamouri, S., Bouhadjar, L., Boucherdoud, A. (2018). Maghnite- $\mathrm{H}^{+}$as Inorganic Acidic Catalyst in Ring Opening Polymerization of Dodecamethylcyclohexasiloxane. Silicon, In press.

[12] Kherroub, D.E., Belbachir, M., Lamouri, S., Chikh, K. (2018). Acid-activated bentonite Maghnite- $\mathrm{H}^{+}$as a novel catalyst for the polymerization of decamethylcyclopentasiloxane. Bulletin of Materials Science, 41: 36-71. 
[13] Kherroub, D.E., Belbachir, M., Lamouri, S., Bouhadjar, L. (2017). Catalytic Activity of Maghnite- $\mathrm{H}^{+}$in the Synthesis of Polyphenylmethylsiloxane under Mild and Solvent-free Conditions. Periodica Polytechnica Chemical Engineering, 62: 195-201.

[14] Kherroub, D.E., Belbachir, M., Lamouri, S. (2018). Green Polymerization of Hexadecamethylcyclooctasiloxane Using an Algerian Proton Exchanged Clay Called Maghnite- $\mathrm{H}^{+}$. Bulletin of Chemical Reaction Engineering \& Catalysis, 13: 36-46.

[15] Bouhadjar, L., Chikh, K., Kherroub, D.E. eds (2016). Synthèse de matériau organique semiconducteur. European University Publishing.

[16] Kherroub, D.E., Belbachir, M., Lamouri, S. (2017). Activated bentonite (Maghnite- $\mathrm{H}^{+}$) as green catalyst for ring-opening polymerization of 1,3,5,7-tetravinyltetramethylcyclotetrasiloxane. Research on Chemical Intermediates, 43: 5841-5856.

[17] Balinta, R., Cassidy, N.J., Cartmell, S.H. (2014). Conductive polymers: Towards a smart biomaterial for tissue engineering. Acta Biomaterialia, 10: 2341-2353.

[18] Monteiro, D.R., Gorup, L.F., Takamiya, A.S., Ruvollo, A.C., de Camargo, E.R., Barbosa, D.B. (2009). The growing importance of materials that prevent microbial adhesion: antimicrobial effect of medical devices containing silver. International Journal of Antimicrobial Agents, 34: 103-110.

[19] Patil, S.L., Pawar, S.G., Chougule, M.A., Raut, B.T., Godse, P.R., Sen, S., Patil, V.B. (2012). Structural, Morphological, Optical, and Electrical Properties of PANi-ZnO Nanocomposites. International Journal of Polymeric Materials, 61: 809-820.

[20] Chougule, M.A., Patil, S.L., Pawar, S.G., Raut, B.T., Godse, P.R., Sen, S., Patil, V.B. (2012). Development of nanostructured polyaniline-titanium dioxide gas sensors for ammonia recognition. Journal of Applied Polymer Science, 125: 1418-1424.

[21] Wallace, G.G., Spinks, G.M., Kane-Maguire, L.A.P., Teasdale, P.R. eds. (2008). Conductive Electroactive Polymers: Intelligent Materials Systems. USA: Taylor \& Francis.

[22] Nikolaidis, M.G., Ray, S., Bennett, J.R., Easteal, A.J., Cooney, R.P. (2010). Electrospun Functionalized Polyaniline CopolymerBased Nanofibers with Potential Application in Tissue Engineering. Macromolecular Bioscience, 10: 1424-1431.
[23] Ma, G., Liang, X., Li, L., Qiao, R., Jiang, D., Ding, Y., Chen, H. (2014). Cu-doped zinc oxide and its polythiophene composites: Preparation and antibacterial properties. Chemosphere, 100: 146-151.

[24] Nikolaidis, M.G., Bennett, J.R., Swift, S., Easteal, A.J., Ambrose, M. (2011). Broad spectrum antimicrobial activity of functionalized polyanilines. Acta Biomaterialia, 7: 4204-4209.

[25] Borole, D.D., Kapadi, U.R., Mahulikar, P.P., Hundiwale, D.G. (2006). Electrochemical synthesis and characterization of conducting copolymer: Poly(o-aniline-co-o-toluidine). Materials Science, 60: 337-349.

[26] Mu, S. (2006). Poly(aniline-co-o-aminophenol) nanostructured network: Electrochemical controllable synthesis and electrocatalysis. Electrochimica Acta, 51: 3434-3440.

[27] Meghabar, R., Megherbi, A., Belbachir, M. (2003). Maghnite- $\mathrm{H}^{+}$, an ecocatalyst for cationic polymerization of $\mathrm{N}$-vinyl-2-pyrrolidone. Polymer, 44: 4097-4100.

[28] Kooli, F., Khimyak, Y. Z., Alshahateet, S. F., Chen, F. (2005). Effect of the Acid Activation Levels of Montmorillonite Clay on the Cetyltrimethylammonium Cations Adsorption. Langmuir, 21: 8717-8723.

[29] Hashizum, H. (2002). Basal spacing of montmorillonite/amino acid complexes at different relative humidity. Clay Science, 11: 565-574.

[30] Yahiaoui, A., Belbachir, M., Hachemaoui, A. (2003). An Acid Exchanged Montmorillonite Clay-Catalyzed Synthesis of Polyepichlorhydrin. International Journal of Molecular Sciences, 4: 548-561.

[31] Boutaleb, N., Benyoucef, A., Salavagione, H.J. (2006). Electrochemical behaviour of conducting polymers obtained into clay-catalyst layers. An in situ Raman spectroscopy study. European Polymer Journal, 42: 733-789.

[32] Yahiaoui, A., Belbachir, M., Soutif, J.C., Fontaine, L. (2005). Synthesis and structural analyses of poly (1,2-cyclohexene oxide) over solid acid catalyst. Materials Letters, 59(7): 759-767. 